\title{
EDITORIAL
}

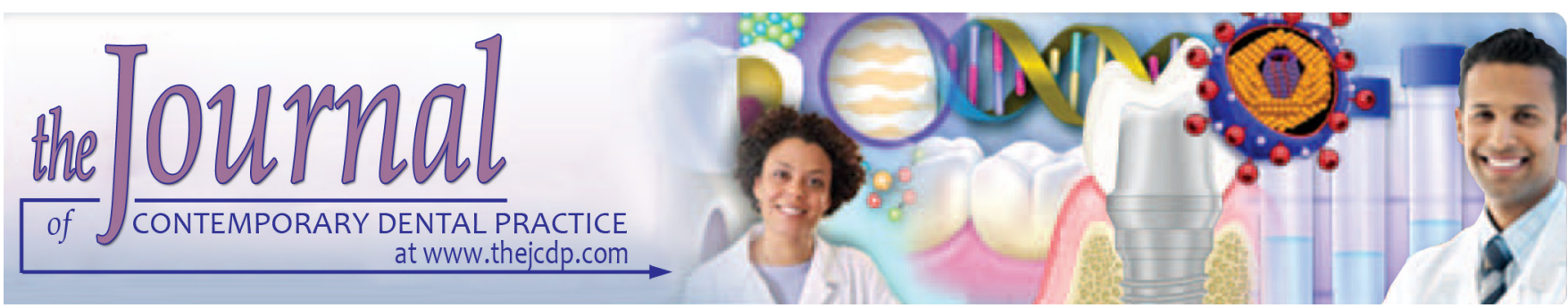

\section{Use of X-ray Diffraction Technique of Hair for Oral Cancer Detection: A Proposal}

\author{
${ }^{1}$ Gargi S Sarode, ${ }^{2}$ Roopa NM, ${ }^{3}$ Nikunj Maniyar, ${ }^{4}$ Sachin C Sarode, ${ }^{5}$ Shankargouda Patil
}

How to cite this article: Sarode GS, Roopa NM, Maniyar N, Sarode SC, Patil S. Use of X-ray Diffraction Technique of Hair for Oral Cancer Detection: A Proposal. J Contemp Dent Pract 2019;20(3):277-278

\section{Source of support: Nil}

\section{Conflict of interest: None}

Techniques that contribute to early diagnosis of oral potentially malignant disorders (OPMDs) and oral squamous cell carcinoma (OSCC) till now followed are vital staining, light-based detection systems along with various histological, cytological, molecular and imaging techniques. ${ }^{1}$ In spite of histopathological technique being the gold standard, diagnosis by taking random biopsies of both clinically normal and the suspected oral area is impractical, since various serious downsides are associated with it and are also not appropriate for repetitive sampling at multiple sites. ${ }^{2}$ A screening test which is non-invasive, safe without exposing an individual to $\mathrm{X}$-radiation and more consistent than any other current method is direly required.

Some pieces of evidence have proved that the changes in molecular structures of tissues secluded from the pretentious region could be correlated with cancerous alterations, e.g., the changes in the molecular and chemical configuration of hair could be related with breast cancer, colon cancer, and Alzheimer's disease. ${ }^{3-5}$ Recently, few studies have been carried out on muscle, collagen, skin and nail tissue samples using fiber diffraction techniques. Thus, there is an alteration in the hair fiber development as

\footnotetext{
${ }^{1-4}$ Department of Oral Pathology and Microbiology, Dr DY Patil Dental College and Hospital, Dr DY Patil Vidyapeeth, Pimpri, Pune, Maharashtra, India

${ }^{5}$ Department of Preventive Dental Sciences, College of Dentistry, Jazan University, Jazan, Kingdom of Saudi Arabia

Corresponding Author: Gargi S Sarode, Department of Oral Pathology and Microbiology, Dr DY Patil Dental College and Hospital, Dr DY Patil Vidyapeeth, Pimpri, Pune, Maharashtra, India, Phone: +919823871462, e-mail: gargi14@gmail.com
}

an impact of developing disorder especially a malignancy (Table 1). The changes in one of the regions of interest have been suggested of an increased lipid content. ${ }^{6}$

Many investigators have done analyses of hair by X-ray diffraction configuration for the screening of breast cancer successfully. The presence of ring in the patterns of hair $X$-ray diffraction is due to the disparity in the cell membrane structure of the fiber as it is amassed in the follicle. ${ }^{7}$ It is found that an 'additional component' might bind to the alpha-keratin fibers in the intermediate filaments or to other structural components like the lipid bi-layers or the high sulfur matrix. ${ }^{8}$ It has been observed that the $X$-ray diffraction analysis of hair from patients with different cancers show a distinctive ring, with diverse malignancies having specific ring patterning overlaid on the normal hard alpha keratin pattern. This additional scattering ring may help to specify the cancer type as it is observed that the diameter of the lipid rings differs with breast and colon cancers. ${ }^{9,10}$ Moreover, the intensity of lipid ring is found to be consistent with the severity of breast cancer, from being hardly visible in type 1 , grade 1 tumors to quite strong in others. ${ }^{11}$ Han et al. ${ }^{12}$ observed hair of breast cancer patients exhibiting medulla loss with stage-dependent pattern. Study done by James. ${ }^{9}$ on whiskers from nude mice which were implanted subcutaneously along with a human breast cancer cell line showed diminished ring pattern after treatment and follow-up. Though a complete biochemical understanding of the mechanism for the appearance of such lipid rings in the hair structure of cancer patients is not very well clear, many potential hypotheses have been put forth. One such probable theory states that the presence of cancer in the body leads to the integration of extraneous lipid material into hair fibers. Another proposed hypothesis believes that the cytokines and growth factors that are released by cancer cells may disturb the epithelial cellular makeup such as hair follicles resulting in the appearance of additional rings in the hair. ${ }^{13}$

Normally, energy-providing lipids are derived primarily from circulating lipids in the tissues. However, 
Table 1: Studies using hair diffraction technique in various malignancies

\begin{tabular}{lll}
\hline Author & Type of malignancy and method & Results \\
\hline James et al. 1999 & Breast cancer by synchrotron X-ray diffraction & d spacing $4.44 \pm 0.06 \mathrm{~nm}$ \\
Meyer P, James VJ. 2001 & Breast cancer by synchrotron X-ray diffraction & d spacing $4.76 \pm 0.1 \mathrm{~nm}$ \\
James VJ. 2003 & Colon cancer by synchrotron X-ray diffraction & d spacing $4.71 \pm 0.05 \mathrm{~nm}$ \\
James VJ et al. 2005 & Animal model of breast cancer by X-ray diffraction & d spacing $9.9 \pm 0.2 \mathrm{~nm}$ \\
Corino GL and French PW 2008 & Breast cancer by synchrotron X-ray diffraction & d spacing $4.76 \pm 0.07 \mathrm{~nm}$ \\
Mistry DAH et al. 2012 & Breast cancer by small angle X-ray scattering一wide & Q space of $1.32 \pm 0.02$ \\
& angle X-ray scattering (saxs-waxs) & angstroms \\
Han SM, et al. 2016 & Breast cancer by X-ray fluorescence analysis & Medullary space absent \\
\hline
\end{tabular}

Flowchart 1: Proposed use of hair diffraction technique in oral cancer detection

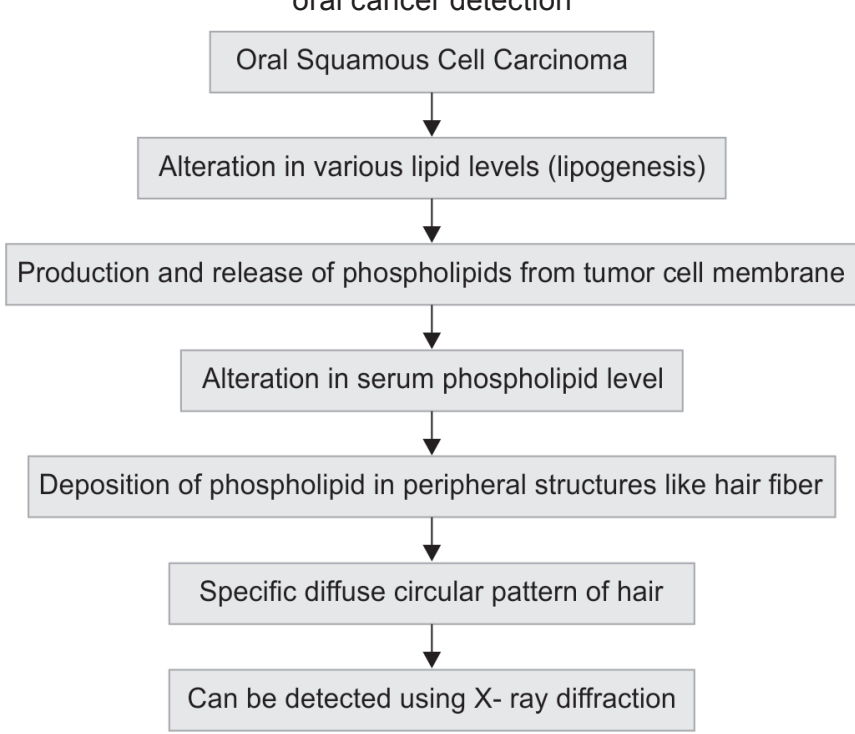

in growing neoplasms, including OSCC, the energy source is chiefly offered by the lipids from de novo synthesis. There are elevated expressions of various lipogenic genes like Fasn in OSCC. Thus, it is well proven that lipogenic genes play an important role in the establishment of the primary tumor. Numerous studies validate the function of fatty acid synthase in stimulation of cell cycle and apoptosis inhibition in various malignancies. Thus, lipogenesis is closely linked to tumorigenesis. These lipids are predominantly seen associated with the cellular and intracellular membrane of cancer cells. ${ }^{14,15}$

So, it is hypothesized that OSCC produces and releases phospholipids, probably from the tumor cell membrane, which enter the circulation and are incorporated into the matrix of the hair fiber resulting in the appearance of an additional component in the regular pattern represented by a circular feature when the hair is subjected to X-ray diffraction (Flowchart 1). This method of X-ray diffraction of hair could prove to be a novel, sensitive and specific diagnostic screening test for various malignancies like OSCC. It could be used for identifying high-risk patients for close follow-up and to detect susceptible individuals without OPMDs. Thus, it is suggested to have more research to find the potential relevance and the place that a specific change in the hair fiber diffraction might have in the diagnosis and management of OSCC. This simple, easy and economical method of X-ray techniques where radiations are used without exposing them to the oral cancer patients could also be used to reveal the overall health-status in future.

\section{REFERENCES}

1. Carreras-Torras C, Gay-Escoda C. Techniques for early diagnosis of oral squamous cell carcinoma: Systematic review. Medicina Oral Patología Oral Y CirugíaBucal 2015; 20(3):305-315.

2. Bremmer JF, Braakhuis BJ, Ruijter-Schippers HJ, et al. A noninvasive genetic screening test to detect oral preneoplastic lesions.

3. James VJ, Willis BE. Molecular changes in skin predict predisposition to breast cancer. J Med Genet 2002;39(2):E1.

4. James VJ. Fibre diffraction from a single hair can provide an early non-invasive test for colon cancer. Med Sci Monitor 2003;11:79-84.

5. James VJ, Richardson JC, Robertson TA, et al. Fibre diffraction of hair can provide a screening test for Alzheimer's Disease: a human and animal model study. Med Sci Monitor 2005;11:53-57.

6. Mistry DAH, Haklani J, French PW. Identification of Breast Cancer-Associated Lipids in Scalp Hair. Breast Cancer: Basic Clin Res 2012;6:113-123

7. James V, Kearsley J, Irving T, et al. Using hair to screen for breast cancer. Nature 1999;398:33-34.

8. Lawson JS, Tran DD. Localised breast cancers may have systemic influences on skin and hair. J Clin Pathol 2007;60:180184.

9. James VJ. Fiber diffraction of skin and nails provides an accurate diagnosis of malignancies. Int J Cancer 2009;125:133-138.

10. James VJ. A place for fiber diffraction in the detection of breast cancer? Cancer Detect Prev 2006;30(3):233-238.

11. James V, Corino G, Robertson T, et al. Early diagnosis of breast cancer by hair diffraction. Int J Cancer 2005;114:969-972.

12. Han SM, Chikawa JI, Jeon JK, et al. Synchrotron Nanoscopy Imaging Study of Scalp Hair in Breast Cancer Patients and Healthy Individuals: difference in Medulla Loss and Cortical Membrane Enhancements. Microsc Res Tech2016;79(1):23-30.

13. Corino GL, French PW. Diagnosis of breast cancer by X-ray diffraction of hair. Int J Cancer 2008;122: 847-856.

14. Kuemmerle NB, Rysman E, Lombardo PS, et al. Lipoprotein lipase links dietary fat to solid tumor cell proliferation. Mol Cancer Ther 201 1;10(3):427-436.

15. Nomura DK, Long JZ, Niessen S, et al. Monoacylglycerol lipase regulates a fatty acid network that promotes cancer pathogenesis. Cell 2010;140(1):49-61. 